ventilation may have had a protective effect in the dependent areas, which is an intriguing result that merits further study. However, the superiority of liquid ventilation over conventional treatments has yet to be demonstrated and long-term safety in regard to the effects of perfluorocarbons on the immune system remains an important obstacle. The introduction of surfactant to clinical practice has made a significant impact on the treatment of hyaline membrane disease. However, the cost of this therapy when applied to ARDS, which seems to be only associated with a brief reduction in ventilator dependency, precludes its widespread application. Regardless, surfactant administration initiates a dynamic process where compliance rapidly changes, in the hours following its application, requiring frequent ventilator adjustments. As the authors appropriately pointed out, the dynamic improvement in compliance may have created cyclic distention in dependent areas due to the lack of adjustment of the positive end expiratory pressure (PEEP). The experimental scenario created by $\mathrm{Dr}$. Viana et al. teaches us that we cannot underestimate the importance of applying the appropriate amount of PEEP to maintain alveolar recruitment. When PEEP succeeds in keeping open otherwise unstable units, it diminishes lung heterogeneity and decreases stress injury. However, the application of PEEP to a rapidly changing lung, due to surfactant administration, requires frequent adjustments. To maintain the strategy of keeping the lung open, tactics need to change e.g. initial recruitment maneuvers are followed by adjustments of PEEP as compliance change.
Nevertheless, even though there was a placebo and control group pitched against three treatment groups, I concur that this experiment was a " 2 horse race" as recently labeled by Kavanagh. ${ }^{5}$ Recruited versus non-recruited lung strategy is the final comparison, rather than a particular technique of mechanical ventilation. The different technologies are tools or tactics that are subordinated to a strategy. It is important to keep the lung recruited during the ventilatory cycle regardless of the technique. This last could be obtained with high frequency ventilation, liquid ventilation or adequate use of PEEP.

\section{References}

1. Viana MEG, Sargentelli GA, Arruda ALM, Wiryawan B, Rotta AT. O impacto de estratégias de ventilação mecânica que minimizam o atelectrauma em um modelo experimental de lesão pulmonar aguda. J Pediatr (Rio J). 2004;80:189-96.

2. Marini JJ, Gattinoni L. Ventilatory management of acute respiratory distress syndrome: a consensus of two. Crit Care Med. 2004;32:250-5.

3. Chu EK, Whitehead T, Slutsky SA. Effects of cyclic opening and closing at low- and high-volume ventilation on bronchoalveolar lavage cytokines. Crit Care Med. 2004;32:168-74.

4. Kisala JM, Ayala A, Stephan RN, Chaudry IH. A model of pulmonary atelectasis in rats: activation of alveolar macrophage and cytokine release. Am J Physiol. 1993;264:610-14.

5. Kavanagh BP. ARDS: ventilation with $6-8 \mathrm{ml} / \mathrm{kg}$ is a standard for all? In: Current Concepts in Pediatric Critical Care Course. Shanley TP, editor. Des Plaines, IL: Society of Critical Care Medicine; 2004. p. 137-144.

\title{
Reflux esophagitis in infants: current knowledge and future challenges
}

\author{
Elisa de Carvalho', Ana Aurélia R. Silva ${ }^{2}$, Ana Raquel M. Franco ${ }^{3}$
}

\begin{abstract}
The pathological processes of the esophagus within the pediatric age group had been little studied and valued until recently, when evolution in diagnostic methods such as upper gastrointestinal endoscopy (UGIE) made
\end{abstract}

1. MSc. Coordinator of the medical residency program in Pediatric Gastroenterology, Hospital de Base do Distrito Federal. Professor, School of Medicine, Escola Superior de Ciências da Saúde, Brasília, DF, Brazil. President of the Pediatric Gastroenterology Department of Distrito Federal Society of Pediatrics.

2. Pediatrician, Division of Pediatric Gastroenterology, Hospital de Base do Distrito Federal, Brasília, DF, Brazil.

3. MSc. Pediatrician, Division of Pediatric Gastroenterology, Hospital de Base do Distrito Federal, Brasília, DF, Brazil. advancements in knowledge possible. Today we know that cow's milk allergy, dysmotility, certain infections, traumas, caustic substances and gastroesophageal reflux (GER) can cause esophageal infirmities (current knowledge). However, certain important aspects have not yet been established, such as the meaning and development of histological esophagitis in infants (future challenges), subjects dealt with in the excellent piece of research published by Vieira et al. ${ }^{1}$

The authors, ${ }^{1}$ national references in pediatric UGIE, analyzed the presence or absence of reflux esophagitis, by means of comparison of UGIE and histology of the esophagus. They included 167 infants referred for further investigation 
of symptoms suggestive of reflux esophagitis (RE): irritability $(100 \%)$, regurgitation $(95.8 \%)$, refusal to eat $(25.7 \%)$, failure to thrive $(10.8 \%)$ and respiratory manifestations ( $3 \%)$. Patients carrying co-morbid conditions were excluded and so were those using medication to inhibit or neutralize peptic acid secretion. In this experiment they observed the presence of histological esophagitis in the absence of macroscopic abnormalities and also an absence of histological esophagitis (conventional microscopy) associated with endoscopic esophagitis.

The presence of histological esophagitis without endoscopic esophageal lesions had already been described in the $80 \mathrm{~s}^{2}$ Since then, other studies have been performed and, currently there is a consensus in the pediatric age group that a normal UGIE does not exclude the possibility of histological esophagitis, and that esophageal biopsy is indicated for patients referred for endoscopic assessment with suspected gastroesophageal reflux disease (GERD). ${ }^{3}$

In the research published by Vieira et al., ${ }^{1}$ eight patients had an endoscopic diagnosis of esophagitis in association with normal histology and all of these had level I esophagitis (non-erosive). Other authors observed that enanthema of the esophageal mucosa may not have any histological correspondence with reflux esophagitis. Studies show the predominance of disagreement between endoscopic and histological results in milder cases, while agreement between the two diagnostic tests predominates in more severe forms. ${ }^{4,5}$

The authors ${ }^{1}$ used the Tytgat classification, which does not take into account the presence or absence of Barrett's esophagus, but describes non-erosive abnormalities observed in the discrete esophagitis commonly observed among infants. However, as findings of erythema, edema, loss of shine and friability in the distal esophagus are controversial choices for esophagitis diagnosis, with interpretations varying greatly from one endoscopist to another, the inclusion of these parameters may have increased the disagreement between macroscopic and histological findings. In contrast, the presence of esophageal erosion is less subject to observer interpretation. ${ }^{4}$ Thus, corroborating these observations, all five patients with erosive esophagitis presented reflux esophagitis on histology.

We also emphasize that esophageal biopsy plays an important role, as much in cases of normal examinations or mild abnormalities as in cases of erosive esophagitis. This feature is also an interesting subject of discussion with endoscopists treating adults, who often do not proceed in this manner. Pediatric UGIE has presented many improvements during the last 25 years and much has been and continues to be learnt from endoscopists working with adults. Nevertheless, taking into account the peculiarities of children, certain routines should be established by professionals working in pediatrics, always seeking answers to the gaps in our current knowledge.

If the edema, erythema and friability commonly observed in children are non-specific, findings from histological examination and morphometric studies of the esophageal mucosa allow an etiologic diagnosis of reflux esophagitis if characteristic alterations such as eosinophil infiltrates, increased total epithelial and basal cell thickness, and elongation of stromal papillae are seen. ${ }^{6}$ Furthermore, histopathology allows the investigation of other diagnostic possibilities such as infectious esophagitis (Herpes virus, cytomegalovirus, candida), Barrett's esophagus, dysplasias, adenocarcinoma and eosinophilic esophagitis. It is important to rule out the latter, since, like peptic esophagitis, eosinophilic esophagitis can progress to esophageal stenosis, while it differs from that condition in not responding well to anti-GER treatment, corticoid therapy being indicated instead. In such cases, the high eosinophil density ( $>20$ per high power field) and the presence of eosinophils in the proximal esophagus favor the hypothesis of eosinophilic esophagitis. ${ }^{7}$

Another important factor is the criteria used to indicate UGIE for RE investigation in infants. In order to assess this issue, the first factor that merits attention is that, in the present study, level I esophagitis was the most common abnormality found both at endoscopy (non-erosive in 66 patients - 39.5\%) and histologically (86 patients - 51.5\%). Erosive esophagitis was observed in just five patients. In contrast, El-Serag et al. ${ }^{8}$ recently presented a study involving 402 patients, ranging from 18 months to 25 years of age, suffering from GERD, all neurologically and anatomically normal, who had upper gastrointestinal endoscopy with biopsy. There was a $34.6 \%$ prevalence of erosive esophagitis, increasing in direct proportion with age, and a $1.5 \%$ prevalence of peptic stenosis.

These results demonstrate that the study of GER and GERD in pediatrics is based on distinct groups, such as infants and older children. Infants, because of the peculiarities of the pathophysiologic mechanisms due to immaturity, present a high prevalence of GER during the first year of life, but because of the short duration of these mechanisms, clinical course is generally self-limiting. ${ }^{9-11}$ Thus, the majority of them present either physiological GER or GERD with discrete esophageal complications. Erosive esophagitis is occasionally observed in patients less than one or two years old, without co-morbidity. In contrast, older children, in common with patients with neuropathies, pneumopathies or congenital anomalies of the esophagus, as sufferers from chronic reflux, present a higher prevalence and greater severity of esophageal complications from GERD. 4

Thus, in approaching both diagnosis and treatment account must be taken of the differences between these patients, ${ }^{12}$ including with respect of criteria used to indicate UGIE and biopsy, ${ }^{13}$ since, while upper gastrointestinal endoscopy is considered a safe and effective procedure in pediatrics, it is also expensive, invasive and requires sedation or anesthesia in the majority of children.

The basis for establishing these criteria is still unclear. Despite the significant progress achieved in recent decades, certain questions remain unanswered. Questions such as: 
the risk of an infant with minimal histological abnormalities progressing to severe esophageal complications, whether the infant's symptoms can be explained by mild histological abnormalities and the possibilities of an infant suffering from physiological GER presenting discrete histological abnormalities with no clinical or future repercussions (future challenges). The search for answers to these questions is not easy because it involves research ethics in that we would have to indicate invasive examinations for infants that are progressing well clinically.

Nevertheless, we do know that at four months $67 \%$ of infants regurgitate, although in general regurgitations resolve spontaneously. At one year just $5 \%$ of children continue regurgitating. ${ }^{11}$ Only $2 \%$ of all these infants require specialized care and medical intervention. ${ }^{9}$ Despite this, because the condition causes the family anxiety and the patient a certain discomfort, many parents seek medical help because their children regurgitate too much (current knowledge).

Thus, in an era in which GER is often diagnosed, endoscopic assessment should be indicated for patients presenting clinical status characteristic of the esophageal complications of GERD, most often observed among older children and patients with co-morbidity. Diagnostic investigation of infants who regurgitate, but gain weight satisfactorily and do not exhibit other signs or symptoms is not indicated in clinical practice. The North American Society for Pediatric Gastroenterology and Nutrition (NASPGAN) recommends that, once other causes of vomiting have been ruled out, infants presenting regurgitation and irritability should undergo a two-week therapeutic test involving a hypoallergenic diet and acid suppression, either sequentially or simultaneously. ${ }^{14}$ If no improvement is seen, examinations ( $\mathrm{pH}$ measurement or UGIE with biopsy) would be indicated after this period. There is consensus that non-erosive or exclusively histological reflux esophagitis responds well to treatment based on conservative measures and $\mathrm{H}_{2}$ receptor blocking agents, of which the most often used in pediatrics is ranitidine (current knowledge). ${ }^{15}$

Summing up, much doubt remains on the subject of the clinical course of reflux esophagitis in infants. In respect of diagnosis, however, we emphasize that the work published by Vieira et al. ${ }^{1}$ has contributed significantly to the advance of our knowledge since it has proven that, when assessing infants referred with suspected GERD, UGIE must be complemented by histological evaluation of the esophagus.

\section{References}

1. Vieira MC, Pisani JC, Mulinari RA. Diagnóstico de esofagite de refluxo em lactentes: a histologia do esôfago distal deve complementar a endoscopia digestiva alta. J Pediatr (Rio J). 2004;80:197-202.

2. Biller JA, Winter HS, Grand RJ, Allred EN. Are endoscopic changes predictive of histologic esophagitis in children? J Pediatr. 1983;103:215-8.

3. Gremse DA. Gastroesophageal reflux disease in children: an overview of pathophysiology, diagnosis, and treatment. J Pediatr Gastroenterol Nutr. 2002;35:S297-9.

4. Hassall E. Macroscopic versus microscopic diagnosis of reflux esophagitis: erosions or eosinophils? J Pediatr Gastroenterol Nutr. 1996;22:321-5.

5. Hyams JS, Ricci A Jr, Leichtner AM. Clinical and laboratory correlates of esophagitis in young children. J Pediatr Gastroenterol Nutr. 1988;7:52-6.

6. Mader AM, Alves MT, Kawakami E, Patricio FR. Reflux esophagitis in children: histological and morphometric study. Arq Gastroenterol. 2002;39:126-31.

7. Khan $S$, Orenstein SR, Di Lorenzo $C$, Kocoshis SA, Putnam PE, Sigurdsson L, et al. Eosinophilic esophagitis: strictures, impactions, dysphagia. Dig Dis Sci. 2003;48:22-9.

8. El-Serag HB, Bailey NR, Gilger M, Rabeneck L. Endoscopic manifestations of gastroesophageal reflux disease in patients between 18 months and 25 years without neurological deficits. Am J Gastroenterol. 2002;97:1635-9.

9. Orenstein SR, Izadnia F, Khan S. Gastroesophageal reflux disease in children. Gastroenterol Clin North Am. 1999;28: 947-69.

10. Shepherd RW, Wren J, Evans S, Lander M, Ong TH. Gastroesophageal reflux in children. Clinical profile, course and outcome with active therapy in 126 cases. Clin Pediatr (Phila). $1987 ; 26(2): 55-60$.

11. Badriul H, Vandenplas Y. Gastro-oesophageal reflux in infancy. J Gastroenterol Hepatol. 1999;14:13-9.

12. Cezard JP. Managing gastro-oesophageal reflux disease in children. Digestion. 2004;69:S3-8.

13. Ashorn M, Ruuska T, Karikoski R, Laippala P. The natural course of gastroesophageal reflux disease in children. Scand J Gastroenterol. 2002;37:638-41.

14. Rudolph CD, Mazur LJ, Liptak GS, Baker RD, Boyle JT, Colletti RB, et al. Guidelines for evaluation and treatment of gastroesophageal reflux in infants and children: recommendations of the North American Society for Pediatric Gastroenterology and Nutrition. J Pediatr Gastroenterol Nutr. 2001;32:S1-31.

15. Vandenplas $Y$, Hegar B. Diagnosis and treatment of gastrooesophageal reflux disease in infants and children. J Gastroenterol Hepatol. 2000; 15:593-603. 